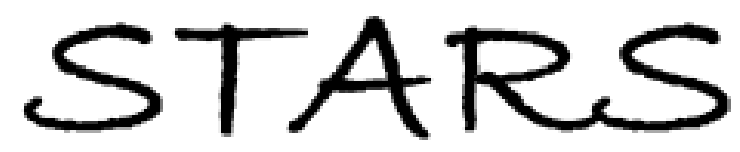

University of Central Florida

STARS

$1-1-2009$

\title{
Measurement of the lattice plane strain and phase fraction evolution during heating and cooling in shape memory $\mathrm{NiTi}$
}

\author{
S. Qiu \\ University of Central Florida \\ V. B. Krishnan \\ University of Central Florida \\ S. A. Padula II \\ R. D. Noebe \\ D. W. Brown
}

See next page for additional authors

Find similar works at: https://stars.library.ucf.edu/facultybib2000

University of Central Florida Libraries http://library.ucf.edu

This Article is brought to you for free and open access by the Faculty Bibliography at STARS. It has been accepted for inclusion in Faculty Bibliography 2000s by an authorized administrator of STARS. For more information, please contactSTARS@ucf.edu.

\section{Recommended Citation}

Qiu, S.; Krishnan, V. B.; Padula, S. A. II; Noebe, R. D.; Brown, D. W.; Clausen, B.; and Vaidyanathan, R., "Measurement of the lattice plane strain and phase fraction evolution during heating and cooling in shape memory NiTi" (2009). Faculty Bibliography 2000s. 2023.

https://stars.library.ucf.edu/facultybib2000/2023

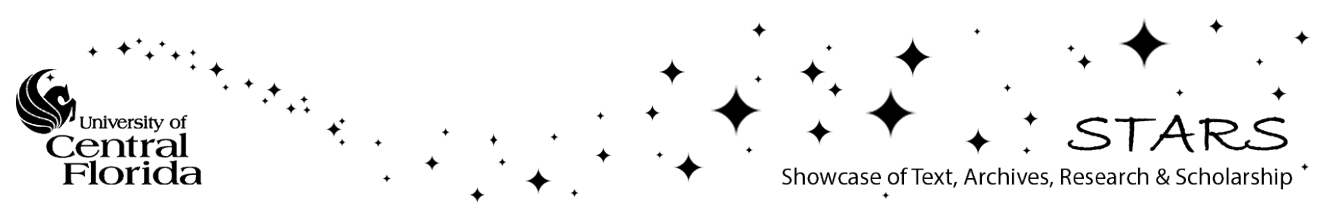




\section{Authors}

S. Qiu, V. B. Krishnan, S. A. Padula II, R. D. Noebe, D. W. Brown, B. Clausen, and R. Vaidyanathan 


\section{Measurement of the lattice plane strain and phase fraction evolution during heating and cooling in shape memory NiTi}

Cite as: Appl. Phys. Lett. 95, 141906 (2009); https://doi.org/10.1063/1.3245308

Submitted: 27 June 2009 . Accepted: 18 September 2009 . Published Online: 08 October 2009

S. Qiu, V. B. Krishnan, S. A. Padula, R. D. Noebe, D. W. Brown, B. Clausen, and R. Vaidyanathan

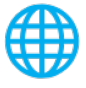

\section{ARTICLES YOU MAY BE INTERESTED IN}

Role of B19' martensite deformation in stabilizing two-way shape memory behavior in NiTi Journal of Applied Physics 112, 093510 (2012); https://doi.org/10.1063/1.4764313

Stress hysteresis and temperature dependence of phase transition stress in nanostructured NiTi-Effects of grain size

Applied Physics Letters 103, 021902 (2013); https://doi.org/10.1063/1.4812643

Elastic modulus of shape-memory NiTi from in situ neutron diffraction during macroscopic loading, instrumented indentation, and extensometry

Applied Physics Letters 86, 081901 (2005); https://doi.org/10.1063/1.1863437

\section{Applied Physics Letters}

Mid-IR and THz frequency combs special collection 


\title{
Measurement of the lattice plane strain and phase fraction evolution during heating and cooling in shape memory NiTi
}

\author{
S. Qiu, ${ }^{1}$ V. B. Krishnan, ${ }^{1}$ S. A. Padula II, ${ }^{2}$ R. D. Noebe, ${ }^{2}$ D. W. Brown, ${ }^{3}$ B. Clausen, ${ }^{3}$ and \\ R. Vaidyanathan ${ }^{1, a)}$ \\ ${ }^{1}$ Advanced Materials Processing and Analysis Center (AMPAC); Mechanical, Materials, and Aerospace \\ Engineering Department, University of Central Florida, Orlando, Florida 32816, USA \\ ${ }^{2}$ NASA Glenn Research Center, Materials and Structures Division, Cleveland, Ohio 44135, USA \\ ${ }^{3}$ Los Alamos National Laboratory, Los Alamos, New Mexico 87545, USA
}

(Received 27 June 2009; accepted 18 September 2009; published online 8 October 2009)

\begin{abstract}
We report on in situ neutron diffraction measurements during heating and cooling through the phase transformation in shape memory NiTi. The lattice plane specific strain evolution remains linear with temperature and is not influenced by intergranular stresses, enabling the determination of the thermal expansion tensor of $B 19^{\prime}$ NiTi. The neutron measurements are consistent with macroscopic dilatometric measurements and a 30000 grain polycrystalline self-consistent model. The accommodative nature of $B 19^{\prime} \mathrm{NiTi}$ results in macroscopic shape changes being offset (with temperature) from the start and finish of the transformation. The texture does not evolve in the absence of biasing stresses. (c) 2009 American Institute of Physics. [doi:10.1063/1.3245308]
\end{abstract}

Shape memory alloys (SMAs) have the ability to recover their original predeformed shape when heated through a phase transformation. In the case of NiTi, shape recovery occurs as a result of a thermoelastic phase transformation from a monoclinic, $B 19^{\prime}$, martensitic structure at low temperatures to a cubic, $B 2$, austenitic structure at high temperatures. The shape recovery can occur against external loads enabling work output in actuator applications. ${ }^{1-4}$ A comprehensive understanding of these alloys, especially in polycrystalline form, remains elusive due to the challenge of making direct connections between the lattice strain, phase volume fraction, and texture evolution associated with the phase transformation at the atomistic scale, and macroscopically measurable properties such as transformation temperatures, work output, thermal expansion, etc. The objective of this work is to establish such connections by performing in situ neutron diffraction to quantify the lattice strain, phase volume fraction, and texture evolution as the $B 19^{\prime}$ phase transforms to the $B 2$ phase during heating and transforms back during cooling, in a nominally unloaded bulk sample. Even though neutron diffraction has been successfully utilized to study bulk NiTi samples previously (e.g., Refs. 5-9), no experiments have been done to quantitatively follow the phase transformation associated with shape memory behavior in the absence of external loads. Implicit in the nature of the diffraction technique is that it provides direct observations, instead of the commonly used indirect assessments ${ }^{10}$ [e.g., through differential scanning calorimetry (DSC), dilatometry, or resistivity measurements] of the phase transformation. In addition to making these connections between atomic scale measurements by neutron diffraction and macroscopic measurements by extensometry, this work is further motivated by a need to make available parametric and experimental input for various existing models of shape memory behavior (e.g., Refs. 11 and 12).

Ten millimeter diameter rods of $\mathrm{Ni}_{49.9} \mathrm{Ti}_{50.1}$ were obtained in the hot-rolled/hot-drawn and hot-straightened con-

${ }^{a)}$ Electronic mail: raj@mail.ucf.edu. dition and were reduced to cylindrical specimens $5.08 \mathrm{~mm}$ in diameter and $15.24 \mathrm{~mm}$ in gauge length. The martensite finish, martensite start, austenite start, and austenite finish, were determined by DSC to be $46,71,86$, and $109 \pm 2{ }^{\circ} \mathrm{C}$, respectively. No intermediate phase, e.g., $R$-phase, was observed. In situ neutron diffraction measurements were performed in "time-of-flight" mode using the SMARTS ${ }^{13}$ at Los Alamos National Laboratory (LANL). The sample was subjected to two heating/cooling cycles at a rate of $15{ }^{\circ} \mathrm{C} / \mathrm{min}$ between 25 and $175^{\circ} \mathrm{C}$, with neutron spectra being acquired during the second cycle. The first cycle was performed to relieve residual stress resulting from machining and stabilize material behavior. The second cycle was interrupted at a total of 27 selected temperatures to record neutron spectra. At each temperature, a holding period of $5 \mathrm{~min}$ was allowed for the temperature to equilibrate and $30 \mathrm{~min}$ to acquire neutron spectra. The macroscopic strain was monitored with an extensometer $(10 \mathrm{~mm}$ gauge length and strain resolution of 5 $\left.\times 10^{-5}\right)$. The Rietveld refinement technique, ${ }^{14}$ implemented in the LANL code General Structure Analysis System (GSAS), ${ }^{15}$ was used to analyze the acquired neutron spectra.

Figure 1 shows the evolution with temperature of the macroscopic strain (from extensometry) and volume percent

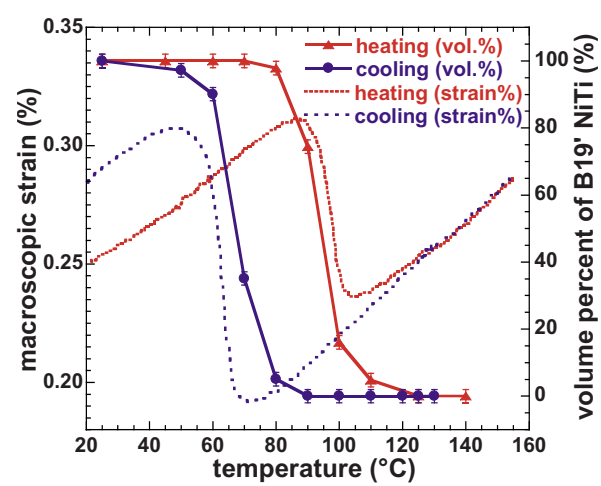

FIG. 1. (Color online) Evolution of macroscopic strain from extensometry (dotted lines) and volume percent of $B 19^{\prime}$ phase from Rietveld refinement of neutron spectra (solid lines) with temperature. 

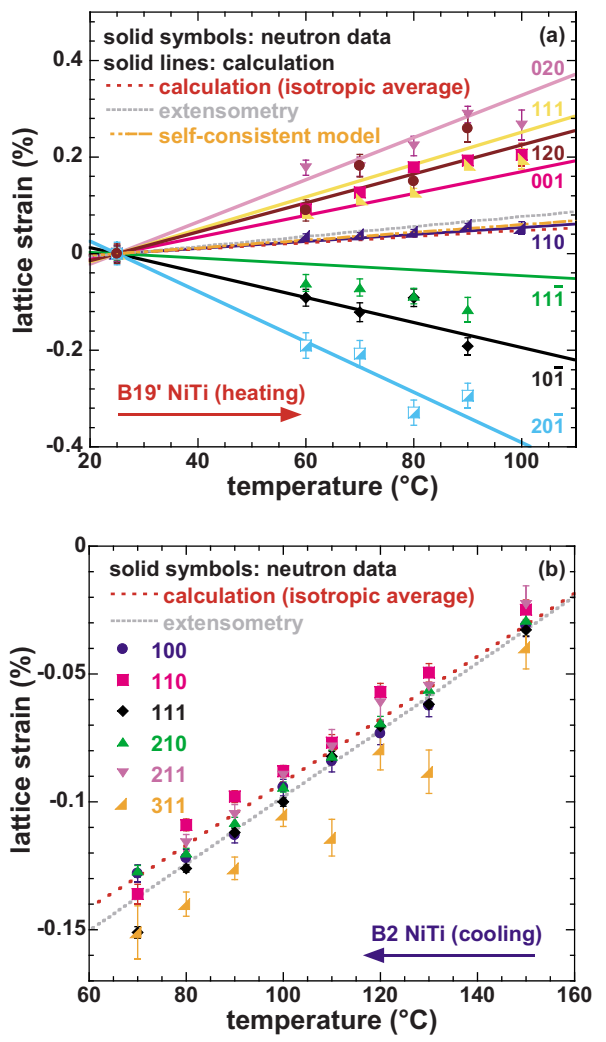

FIG. 2. (Color online) Lattice strain evolution as a function of temperature in (a) $B 19^{\prime}$ NiTi during heating and (b) B2 NiTi during cooling. The data shown here are from lattice planes parallel to the length of the sample.

of $B 19^{\prime}$ phase (by Rietveld refinement). While a one to one correspondence between the two curves is observed, careful examination shows nascent $B 2$ phase being formed during heating with no detectable change in the macroscopic shapechange strain. The last $B 19^{\prime}$ variants to transform to the $B 2$ phase also appear to not affect the macroscopic shape-change strain. Similar observations were made and substantiated by qualitative examination of spectra close to the start and finish of the phase transformation during heating and cooling. For example, at temperatures above $102{ }^{\circ} \mathrm{C}$, no shape-change strains were measurable on the extensometer while the neutron spectrum at $110{ }^{\circ} \mathrm{C}$ still showed about 5.5 vol \% of $B 19^{\prime}$ phase. This difference can be attributed to the accommodative nature of the $B 19^{\prime}$ phase, wherein the elastic, thermal and allotropic mismatch is minimized ${ }^{16,17}$ close to the start and finish of the phase transformation, indicating that the transformation temperatures cannot be precisely captured by techniques that rely on measuring macroscopic shape changes (e.g., ASTM F2082-03 ${ }^{10}$ ).

Peak positions and interplanar spacings were determined by single peak fitting in GSAS. ${ }^{9}$ Strains in the respective phases were quantified from,

$$
\varepsilon_{h k l}=\frac{d^{h k l}-d_{0}^{h k l}}{d_{0}^{h k l}}
$$

where $d_{0}^{h k l}$ is the planar $d$-spacing at an initial condition and $d^{h k l}$ is the planar $d$-spacing at the selected temperature. The value of $d_{0}^{h k l}$ was arbitrarily measured for the $B 19^{\prime}$ phase at $25^{\circ} \mathrm{C}$ and for the $B 2$ phase at $175^{\circ} \mathrm{C}$. The choice of the reference temperatures is not significant since relative rather than absolute strains are considered in the analyses.

The solid symbols in Fig. 2(a) are strains determined
TABLE I. Components of the thermal expansion tensor and CTE determined from neutron spectra, extensometry, and a self-consistent model $\left(10^{-6} /{ }^{\circ} \mathrm{C}\right)$ in $B 19^{\prime}$ and $B 2 \mathrm{NiTi}$ during heating and cooling.

\begin{tabular}{lcrrr}
\hline \hline & & $\begin{array}{c}\text { Heating } \\
\left(10^{-6} /{ }^{\circ} \mathrm{C}\right)\end{array}$ & $\begin{array}{c}\text { Cooling } \\
\left(10^{-6} /{ }^{\circ} \mathrm{C}\right)\end{array}$ \\
\hline \multirow{6}{*}{ B19' NiTi } & Thermal expansion & & & \\
& tensor components & $\alpha_{11}$ & -47.2 & -30.8 \\
& & $\alpha_{22}$ & 43.8 & 32.1 \\
& & $\alpha_{33}$ & 22.7 & 27.3 \\
& & $\alpha_{31}$ & 29.0 & 32.4 \\
& & & 6.4 & 9.5 \\
& CTE $^{\mathrm{a}} \mathrm{NiTi}$ & & 8.1 & 10.9 \\
& CTE (extensometry) & & 10.3 & 9.0 \\
& CTE $^{\mathrm{b}}$ & & 13.0 & 13.1 \\
& $\mathrm{CTE}$ (extensometry) & 12.4 & 12.3 \\
\hline \hline
\end{tabular}

${ }^{\mathrm{a}}$ Isotropic average.

${ }^{\mathrm{b}}$ Self-consistent model.

using Eq. (1) along directions normal to various $B 19^{\prime}$ planes. We particularly note that the strains increase or decrease linearly with temperature despite being associated with varying volume percent of the $B 19^{\prime}$ phase (i.e., from being $100 \%$ at $25{ }^{\circ} \mathrm{C}$ to $16 \%$ at $100{ }^{\circ} \mathrm{C}$ ). While the increase or decrease is attributed to anisotropy arising from crystal symmetry (or lack thereof), the linearity is attributed to the accommodative nature of the $B 19^{\prime}$ phase and its ability to detwin and to selectively transform to the $B 2$ phase, thereby accommodating any associated intergranular stresses arising from either like $B 19^{\prime}$ grains or $B 2$ grains. ${ }^{16-18}$ A linear fit of data from

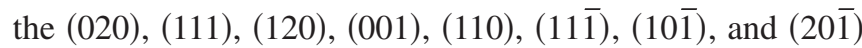
planes corresponds to the coefficients of thermal expansion (CTE) in the direction normal to these planes, and were determined to be $42.2,36.8,30.7,26.6,8.7,-17.1,-25.3$, and $-49.5\left(\times 10^{-6} /{ }^{\circ} \mathrm{C}\right)$, respectively. Adapting from Ref. 19 , the thermal expansion tensor was determined from the aforementioned neutron measurements as outlined in the following. For a monoclinic crystal, the thermal expansion $A_{r}$ in the direction of a unit vector $l$ is given by

$$
A_{r}=l_{T} \alpha_{i j} l=\left(\begin{array}{lll}
l_{1} & l_{2} & l_{3}
\end{array}\right)\left(\begin{array}{ccc}
\alpha_{11} & 0 & \alpha_{13} \\
0 & \alpha_{22} & 0 \\
\alpha_{13} & 0 & \alpha_{33}
\end{array}\right)\left(\begin{array}{l}
l_{1} \\
l_{2} \\
l_{3}
\end{array}\right) \text {, }
$$

where $\alpha_{i j}$ is the thermal expansion tensor. In matrix notation,

$$
A=\Theta \alpha \Rightarrow\left(\begin{array}{c}
A_{1} \\
A_{2} \\
: \\
A_{n}
\end{array}\right)=\left(\begin{array}{cccc}
l_{1}^{2} & l_{2}^{2} & l_{3}^{2} & 2 l_{1} l_{3} \\
m_{1}^{2} & m_{2}^{2} & m_{3}^{2} & 2 m_{1} m_{3} \\
: & : & : & : \\
n_{1}^{2} & n_{2}^{2} & n_{3}^{2} & 2 n_{1} n_{3}
\end{array}\right)\left(\begin{array}{c}
\alpha_{11} \\
\alpha_{22} \\
\alpha_{33} \\
\alpha_{13}
\end{array}\right) .
$$

The lattice parameters required to account for nonorthogonality in the monoclinic structure were determined to be $a=0.467 \mathrm{~nm}, b=0.414 \mathrm{~nm}, c=0.291 \mathrm{~nm}$, and $\beta=97.55^{\circ}$ from Rietveld refinement of the neutron spectrum at $25^{\circ} \mathrm{C}$. Even though four values, $A_{1}, A_{2}, A_{3}$, and $A_{4}$, were sufficient to determine $\alpha$ in Eq. (3) for the $B 19^{\prime}$ phase, the best value was obtained by a least-squares approach,

$$
\alpha=\left(\Theta_{T} \Theta\right)^{-1} \Theta_{T} A .
$$

The components of the thermal expansion tensor thus determined are reported in Table I. The monoclinic symmetry of 
the $B 19^{\prime}$ phase requires four independent constants to capture the thermal expansion anisotropy in tensorial form while thirteen constants are needed to capture the elastic anisotropy in tensorial form. To assess whether four constants were adequate to successfully describe the measured lattice strain anisotropy, the thermal expansion tensor thus determined was used to obtain the CTE from Eq. (2) in the eight aforementioned directions. The results are shown in Fig. 2(a) as solid lines which reasonably capture the thermal expansion anisotropy in the $B 19^{\prime}$ phase and points to a diminished influence of the elastic strain anisotropy as a result of the relaxation of intergranular stresses. In addition, a 30000 grain self-consistent polycrystalline deformation model ${ }^{20,21}$ with elastic stiffness constants from $a b$ initio calculations ${ }^{22}$ and experimental validation ${ }^{7}$ was also used to assess the role of intergranular stresses. The model prediction was substantially better with the measured values when the intergranular stresses were allowed to fully relax, and the average CTE from this model $\left(\mathrm{CTE}^{\mathrm{b}}\right)$ is included in Table I and also shown in Fig. 2(a). The coordinate axes of the thermal expansion tensor were transformed to obtain principal CTEs, further averaged to obtain an isotropic, volume-averaged value $\left(\mathrm{CTE}^{\mathrm{a}}\right)$ and reported in Table $\mathrm{I}$, along with values from extensometry (CTE) measured in this work. The results compare favorably and also agree with previously reported dilatometric values, e.g., 8.1 (heating) and $8.9 \times 10^{-6} /{ }^{\circ} \mathrm{C}$ (cooling) for the $B 19^{\prime}$ phase. ${ }^{17}$

Figure 2(b) shows the lattice strains with temperature along $\langle 100\rangle,\langle 110\rangle,\langle 111\rangle,\langle 210\rangle,\langle 211\rangle$, and $\langle 311\rangle$ directions in the $B 2$ phase, and no lattice strain anisotropy was observed as would be expected in the absence of the influences of intergranular stresses and elastic anisotropy (since the thermal expansion tensor contains only one independent constant while the stiffness tensor contains three independent constants). This again is the result of the accommodative nature of the $B 19^{\prime}$ phase (when it coexists with the $B 2$ phase) and can be directly contrasted with the stress-induced transformation in NiTi (Ref. 9) and plasticity in stainless steel. ${ }^{23}$ The corresponding average values for the $B 2$ phase from neutron measurements and extensometry are also reported in Table I and compare favorably with previously reported dilatometric values, $12.6 \times 10^{-6} /{ }^{\circ} \mathrm{C}$ (heating) and $11.5 \times 10^{-6} /{ }^{\circ} \mathrm{C}$ (cooling) ${ }^{17}$ Furthermore, the corresponding values for the $B 19^{\prime}$ phase during cooling and the $B 2$ phase during heating are additionally reported in Table I and are consistent with the aforementioned discussion given the reversible nature of the phase transformation.

The texture evolution during heating and cooling in both the $B 19^{\prime}$ and $B 2$ phases was investigated by recourse to a generalized spherical harmonic description of the preferred orientation or texture ${ }^{16}$ in the Rietveld refinement procedure, and no significant evolution was observed. The lack of texture evolution is expected since there is neither external biasing stress (as in e.g., Ref. 9) nor substantial intergranular stress during the transformation, and is consistent with the observed lattice strain evolution with temperature.

The implications of this work which quantitatively links the lattice strain and phase fraction evolution with macroscopic measurements during a shape memory transformation are now highlighted. The measured lattice strain versus temperature response points to the fundamentally accommodative nature of the $B 19^{\prime}$ phase during the transformation that seeks to minimize elastic, thermal, and allotropic mismatch, which was additionally validated in this work using a 30000 grain polycrystalline self-consistent model. From the thermal expansion tensor determined here, the thermal expansion anisotropy of the $B 19^{\prime}$ phase is now known. This quantitative determination of the direction dependent thermal strains is of value in deconvoluting and determining strains purely resulting from the phase transformation (as opposed to elastic strains). Furthermore, the established methodology is important in identifying desirable textures in high temperature SMAs, e.g., NiTiPt, where transformation strains can be smaller. Lastly, this work urges caution in establishing standards based on indirect measurements of the phase transformation (e.g., ASTM F2082-03 ${ }^{10}$ ), given the offset between atomic scale activity and macroscopic behavior attributed to the accommodative nature of the $B 19^{\prime}$ phase-as observed in this work while directly comparing neutron spectra and the extensometry response during the phase transformation.

S.Q., V.B.K., and R.V. acknowledge funding from the NASA Fundamental Aeronautics Program, Supersonics Project (Grant No. NNX08AB51A) and NSF (Grant No. CAREER DMR-0239512). The authors thank T. Sisneros, S. Kabra, J. Wall, and C. Aydiner at LANL for technical support. This work has benefited from the use of the Lujan Neutron Scattering Center at LANSCE, which is funded by the Office of Basic Energy Sciences (DOE). LANL is operated by Los Alamos National Security LLC under DOE under Contract No. DE-AC52-06NA25396.

${ }^{1} \mathrm{~K}$. Bhattacharya, Microstructure of Martensite: Why It Forms and How It Gives Rise to the Shape-Memory Effect? (Oxford University Press, New York, 2003).

${ }^{2}$ K. Bhattacharya and R. D. James, Science 307, 53 (2005).

${ }^{3}$ K. Otsuka and C. M. Wayman, Shape Memory Materials (Cambridge University Press, Cambridge, 1999).

${ }^{4}$ K. Otsuka and X. Ren, Prog. Mater. Sci. 50, 511 (2005).

${ }^{5}$ M. A. M. Bourke, R. Vaidyanathan, and D. C. Dunand, Appl. Phys. Lett. 69, 2477 (1996).

${ }^{6}$ C. R. Rathod, B. Clausen, M. A. M. Bourke, and R. Vaidyanathan, Appl. Phys. Lett. 88, 201919 (2006).

${ }^{7}$ S. Rajagopalan, A. L. Little, M. A. M. Bourke, and R. Vaidyanathan, Appl. Phys. Lett. 86, 081901 (2005).

${ }^{8}$ B. Ye, B. S. Majumdar, and I. Dutta, Appl. Phys. Lett. 91, 061918 (2007).

${ }^{9}$ R. Vaidyanathan, M. A. M. Bourke, and D. C. Dunand, J. Appl. Phys. 86, 3020 (1999)

${ }^{10}$ ASTM F2082-03, Annual Book of ASTM Standards (ASTM, West Conshohocken, PA, 2003).

${ }^{11}$ L. C. Brinson, J. Intell. Mater. Syst. Struct. 4, 229 (1993).

${ }^{12}$ J. G. Boyd and D. C. Lagoudas, Int. J. Plast. 12, 805 (1996).

${ }^{13}$ M. A. M. Bourke, D. C. Dunand, and E. Ustundag, Appl. Phys. A: Mater. Sci. Process. 74, S1707 (2002).

${ }^{14}$ H. M. Rietveld, J. Appl. Crystallogr. 2, 65 (1969).

${ }^{15}$ A. C. Larson and R. B. Von Dreele, LANL Report No. LAUR 86-748, 2004.

${ }^{16}$ R. Vaidyanathan, M. A. M. Bourke, and D. C. Dunand, Acta Mater. 47, 3353 (1999)

${ }^{17}$ K. L. Fukami-Ushiro and D. C. Dunand, Metall. Mater. Trans. A 27, 193 (1996)

${ }^{18}$ D. W. Brown, T. A. Sisneros, B. Clausen, S. Abeln, M. A. M. Bourke, B. G. Smith, M. L. Steinzig, C. N. Tomé, and S. C. Vogel, Acta Mater. 57, 972 (2009).

${ }^{19}$ J. F. Nye, Physical Properties of Crystals (Clarendon, Oxford, 1985).

${ }^{20}$ B. Clausen, C. N. Tomé, D. W. Brown, and S. R. Agnew, Acta Mater. 56, 2456 (2008)

${ }^{21}$ P. A. Turner and C. N. Tomé, Acta Mater. 42, 4143 (1994).

${ }^{22}$ M. Wagner and W. Windl, Acta Mater. 56, 6232 (2008).

${ }^{23}$ M. R. Daymond, M. A. M. Bourke, R. B. Von Dreele, B. Clausen, and T. Lorentzen, J. Appl. Phys. 82, 1554 (1997). 